\title{
O que será da avaliação sem a ética?
}

A obsessão do uso do termômetro nunca fez baixar a temperatura.

PhiLIPPE MeIRIEU

Haverá algo mais educativo e libertador do que exercitarmos nossa capacidade de avaliar a avaliação, reconhecendo que sua complexidade não se encontra na seleção de dados a coletar, mas na decisão do olhar interpretativo que será utilizado?

MARA REgINA DE SORDI

\section{ão se pode deixar de concordar com os que afirmam que} a avaliação é, muitas vezes, "uma pedra no caminho" do trabalho das instituições, das escolas, dos educadores. Dizemos sempre que avaliar não é fácil. A pergunta que imediatamente se propõe é: por quê? Que características tem a avaliação que a tornam "difícil"? O que se exige num processo avaliativo que o faz converter-se freqüentemente num problema para os que com ele estão envolvidos?

Minha área de trabalho é a Filosofia da Educação. A Ética tem sido um espaço privilegiado de minha reflexão. É no âmbito da Filosofia da Educação e da Ética, portanto, que tenho me voltado para as diversas questões que nos desafiam no nosso cotidiano de educadores.

Neste texto, pretendo centrar a reflexão na necessidade da presença da ética no terreno da avaliação. Em um trabalho anterior (Rios, 2000), procurei apontar alguns aspectos desse tema. Aqui, quero levar adiante a discussão, explorando alguns elementos provocativos, encontrados na prática de professores e indicados por

* Terezinha Azerêdo Rıos é doutora em Educação, professora do Mestrado em Educação do Centro Universitário Nove de Julho - Uninove e do Departamento de Teologia e Ciências da Religião da PUC/SP: 〈te.rios@terra.com.br〉. 
eles em algumas situações. Vou destacar uma experiência que, embora tendo um caráter bastante particular, representa, de certa forma, algo que é vivenciado por muitos educadores.

\section{Uma vivência em Moçambique}

De 2004 a 2006, trabalhei como professora num convênio da PUC-SP com a Universidade Pedagógica, em Moçambique. Tratava-se de um mestrado desenvolvido pelo Programa de Estudos Pós-Graduados em Educação/Currículo e cujos alunos eram professores dos diversos cursos da universidade moçambicana. Ali, ministrei a disciplina Avaliação: Teorias e Práticas.

O objetivo central da disciplina, apresentado na proposta de programa, era discutir sobre o significado da avaliação no contexto escolar, identificando suas funções e percebendo suas conseqüências e implicações políticopedagógicas. Buscou-se analisar o processo avaliativo no interior das tendências da educação contemporânea e refletir sobre as políticas de avaliação na educação em Moçambique, seus fundamentos e sua significação na organização curricular da escola daquele país.

No relatório apresentado ao final do trabalho, afirmo que foi uma experiência muito gratificante, pois pude contar, no decorrer dos trabalhos, com a disponibilidade e a atenção de todo o grupo. Todas as propostas apresentadas foram acolhidas com interesse e foi grande 0 envolvimento de todos nas discussões. Revelaram-se a curiosidade e o empenho de ampliar o conhecimento para aprimorar a atuação profissional, especificamente no que diz respeito à avaliação educacional. Pôdese perceber que a exploração sistemática dos conceitos trouxe, a alguns dos participantes, uma nova forma de se apropriar deles.

Num dos momentos do trabalho, depois de discutirmos a natureza da avaliação, suas funções, os tipos de avaliação, solicitei, aos alunos-professores, que indicassem quais eram as certezas e dúvidas que tinham sobre a questão.

No plano das certezas, apontavam-se:

- a importância do processo avaliativo no contexto da educação;

- as vantagens de um olhar crítico sobre a prática pedagógica;

- a necessidade da atenção dos professores para todos os elementos envolvidos nessa prática.
Algumas afirmações já indicavam uma preocupação com o eixo da reflexão que aqui pretendo desenvolver:

- "Tenho certeza de que uma avaliação justa motiva os alunos para a aprendizagem";

- "É preciso ser um bom educador para garantir uma avaliação justa";

- "A avaliação é um gesto crítico que visa trazer a justiça na relação professor-aluno".

No plano das dúvidas, concretizaram-se as preocupações que já se anunciavam nas "certezas":

- "Será que existe um professor que faz uma avaliação justa?";

- “É possível fazer justiça no processo da avaliação?”;

- "A subjetividade do processo de avaliação deixame com uma série de dúvidas quanto à justiça nesse processo".

Esses questionamentos apontavam para um foco comum: será que há realmente possibilidade de haver justiça quando se realiza uma avaliação?

A referência à justiça nos remete imediatamente à necessidade da presença da ética no campo da avaliação. Para além de perguntar por métodos e técnicas de elaboração de instrumentos de avaliação, ou pela objetividade de critérios para organização de exames e provas, os professores faziam emergir o núcleo da ação avaliativa, que se encontra em sua própria definição, se recorrermos à etimologia: avaliar é conferir valor. E qual é o valor da avaliação? Embutida na pergunta pela justiça, havia uma indagação: de que vale a avaliação, se ela não é justa?

\section{Conferir valor}

\section{Conferir valor é algo que marca a intervenção dos seres}

humanos no mundo, como criadores de cultura. A transformação que se opera na realidade, por meio do trabalho, não se dá apenas num aspecto material, como também, e principalmente, num plano simbólico, de atribuição de significados, de valores.

Valores de diferentes naturezas, que se encontram presentes em todas as dimensões das ações e relações dos seres humanos, na sociedade e na história:

- lógicos - quando nos referimos à verdade ou falsidade dos enunciados, das proposições teóricas;

- estéticos - quando se qualificam como belas ou não as criações artísticas;

- econômicos - quando se quantificam as realizações que produzem a vida material; 
...se recorrermos à

etimologia: avaliaré

conferir valor. E qual é

o valor da avaliação?

Embutida na pergunta

pela justiça, havia uma

indagação: de que vale

a avaliação, se ela não

é justa?

- morais - aqueles para os quais quero chamar atenção, que dizem respeito à significação conferida ao comportamento dos indivíduos em sociedade, na sua relação com os outros.

Se a presença dos valores é algo constituinte da ação e da relação entre os seres humanos e se dizemos que avaliar é conferir valor, podemos afirmar que a avaliação faz parte do cotidiano da vida humana. Ouvimos dizer, sempre, que, em todo momento, estamos avaliando: acordamos, chegamos à janela e dizemos que "o dia está bonito"; vemos passar um conhecido na rua e pensamos que sua gravata é "de mau gosto"; assistimos na televisão à descrição de um homicídio e opinamos que é "um crime imperdoável"; lemos o trabalho de um aluno e concluímos que "está regular".

Será que são "avaliações” de natureza idêntica? Sabemos que não, tanto em virtude da "classificação" antes apresentada, quanto dos contextos nos quais se dá o gesto avaliativo. Entretanto, é importante assinalar que, em qualquer espaço em que se realiza esse gesto, sempre se tem uma referência para se afirmar que algo é "bom", "de mau gosto", "imperdoável” ou "regular”. Não avaliamos sem considerar alguns critérios, que constituem uma base para nossos juízos.

É da natureza da avaliação voltar-se para um objeto com a intenção de emitir sobre ele um parecer. Há sempre, no gesto avaliativo, um juízo de valor. Os juízos são atos do pensamento nos quais afirmamos ou negamos algo.

Nos juízos de fato, enunciamos algo que diz respeito a aspectos verdadeiros ou falsos da realidade. Nos juízos de valor, fazemos uma apreciação dos fatos.
Não se diz que se avalia quando apenas se verifica que um corredor percorreu uma distância de 100 metros em 30 segundos. Na verdade, avalia-se quando se julga se isso significou ou não algo importante - o registro de um recorde, por exemplo. Na escola, não haveria sentido em atribuir notas aos trabalhos dos alunos, se não houvesse um referencial segundo o qual se pudesse dizer se aquelas notas indicam algo bom ou mau.

\section{Apontar o positivo e o negativo}

Falamos aqui em presença da ética na avaliação que se realiza no contexto educacional, mais propriamente no contexto escolar. Assim, num processo de educação organizado e sistemático, a avaliação deve caracterizar-se como um olhar crítico, que procura voltar-se para a realidade com a intenção de vê-la com clareza, profundidade e abrangência, buscando superar uma visão ideológica ou preconceituosa, indo às raízes das questões que pretende investigar e enfrentando o desafio de levar em consideração a diversidade e a multiplicidade de pontos de vista com que se defronta.

Avaliar deve ser, então, no sentido que aqui se considera, fazer uma crítica. É preciso cuidado, entretanto, para não ficarmos presos ao sentido que se dá à crítica, no nível do senso comum. Aí, a crítica é considerada uma apreciação que aponta apenas o aspecto negativo do objeto enfocado. Diz-se, então, que criticar é "falar mal": "o aluno criticou a professora", "os pais criticaram a escola", "os professores criticaram o governo".

Isso leva a pensar que talvez a resistência que se tenha à avaliação se justifique em virtude de uma compreensão restrita, que reduz e empobrece a significação do olhar crítico. Sem ter consciência clara disso, muitos professores buscam no desempenho dos alunos somente os aspectos que é preciso corrigir.

É claro que, quando avaliamos, encontramos muitas vezes elementos que precisam ser corrigidos, modificados, superados. Entretanto, se já partimos do pressuposto de que há algo a ser corrigido, nosso olhar pode deixar de enxergar o que está bom, o que merece ser destacado e aprimorado.

0 que afirmamos sobre a atitude crítica nos ajuda a entender, assim, que fazer a crítica a algo não significa apontar só o que é negativo. Ao olhar com clareza, com profundidade e com abrangência, temos a possibilidade de ver o que é bom e o que é mau, o que anda bem e 
o que está inadequado. Assim, podemos nos esforçar para mudar o que não está satisfatório e aperfeiçoar o que julgamos que está indo bem. Por isso é que não faz sentido falar em crítica construtiva ou destrutiva: a crítica alarga e aprofunda nossa visão - o que fazemos a partir daí é o que efetivamente qualifica o processo, do ponto de vista ético.

\section{Dimensões da avaliação}

Talvez a qualificação da avaliação como algo difícil se deva ao fato de ela constituir uma atitude crítica, que nem sempre se assume facilmente. Na verdade, menos que difícil, a avaliação é complexa: o campo da avaliação - especialmente da avaliação educacional - compõese de vários segmentos específicos e o processo avaliativo se constitui de inúmeras dimensões, estreitamente conectadas entre si.

Para falar da presença da ética, como uma dimensão que deve ser constituinte da avaliação, devemos, então, voltar nosso olhar para as dimensões da avaliação.

Há em toda ação avaliativa uma dimensão técnica, que diz respeito ao conhecimento tanto dos objetos ou dos sujeitos a serem avaliados, quanto dos objetivos e dos procedimentos necessários e adequados. Aí também se encontram os referenciais para as verificações. Avaliar pressupõe apontar determinados objetos, estabelecer objetivos que se pretendem alcançar, construir ou selecionar instrumentos para a ação e definir caminhos para atingir o fim.

Por ser fundamental na configuração da avaliação, a dimensão técnica constitui, sem dúvida, o seu suporte. Entretanto, ela só ganha sentido se estiver articulada às outras dimensões. Uma delas é a dimensão política, que guarda referência ao contexto no qual se dá a avaliação, às determinações aí presentes, às pressões para a definição de caminhos.

A outra é a dimensão moral, que diz respeito especificamente à atitude, ao comprometimento dos sujeitos que realizam as ações de avaliação.

Fica, evidente, então, que a avaliação não tem apenas um caráter técnico, não se reduz aos atos de verificar ou conferir ações e resultados. É impossível falar de um processo de avaliação sem fazer referência às determinações a que está constantemente submetido e aos valores que o fundamentam. Avaliar pressupõe definir princípios, em função dos objetivos que se pretende al-

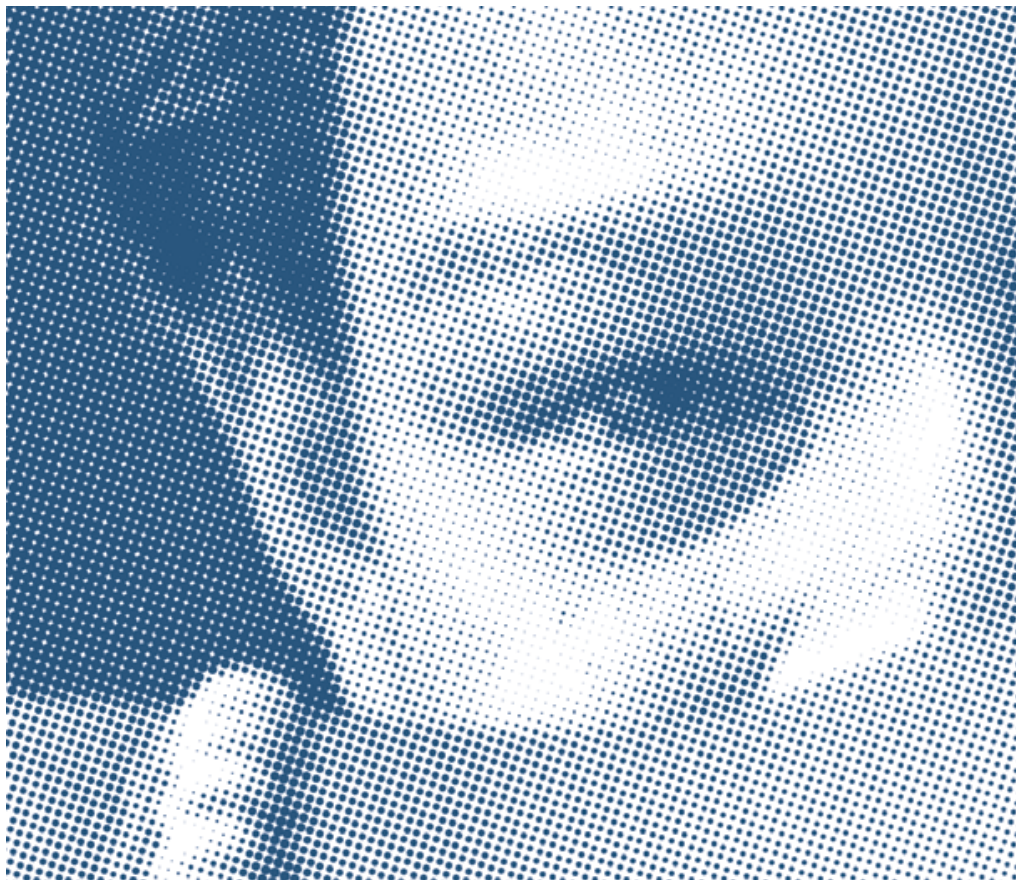

cançar e implica um compromisso dos sujeitos envolvidos na direção desses objetivos.

Muitas vezes, considera-se apenas a dimensão técnica da avaliação, deixando-se de lado os aspectos políticos e, principalmente, os éticos. Assim, a preocupação maior se concentra nos instrumentos, nas medidas, nas representações quantificadas. Não é ruim estar atento a esses elementos. Na verdade, é uma atitude ingênua aquela que despreza os aspectos quantitativos da avaliação.

Romão (1998, p. 48) qualifica como um mito, indicador do caráter ideológico que se encontra muitas vezes no campo da avaliação, a afirmação de que "é preciso eliminar os aspectos quantitativos da avaliação". Recorrendo a Gramsci, o autor afirma que: "já que não pode existir quantidade sem qualidade e qualidade sem quantidade (economia sem cultura, atividade prática sem inteligência e vice-versa), qualquer contraposição dos dois termos é, racionalmente, um contra-senso" (idem).

o que vale assinalar é que, ao se perder de vista o que significam, do ponto de vista ético-político, os aspectos qualitativos, empobrece-se o sentido da avaliação, que faz parte de uma dinâmica mais ampla: a da prática educativa e a da convivência social. Dias Sobrinho (2003, p. 177) confirma a presença da dimensão político-moral quando afirma que 


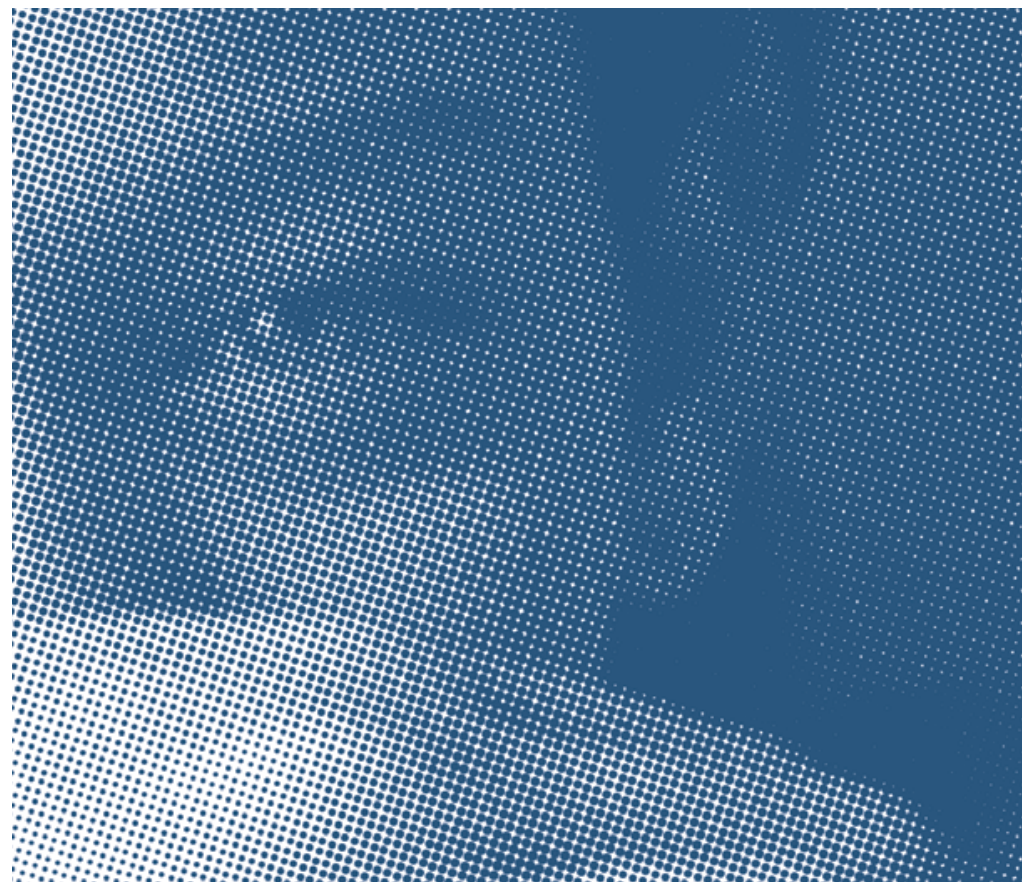

...a avaliação (...) é uma prática social orientada sobretudo para produzir questionamentos e compreender os efeitos pedagógicos, políticos, éticos, sociais, econômicos do fenômeno educativo, e não simplesmente uma operação de medida e muito menos um exercício autocrático de discriminação e comparação.

\section{Ética e moral}

O fato de existir uma dimensão moral na avaliação não implica, entretanto, a presença da ética. Embora haja uma referência constante à ética no trabalho dos educadores, penso que ainda se faz confusão, o que é muito comum, entre ética e moral. É preciso distingui-las, não para separá-las - o que é impossível e sim para que possamos nos referir a elas com mais propriedade.

Enquanto a moral consiste no conjunto de prescrições que orienta a conduta de indivíduos e grupos nas sociedades, a ética se apresenta como um olhar crítico sobre a moral, perguntando pelos fundamentos dos valores que a sustentam.

As ações morais têm sua origem nos costumes de cada sociedade. Esses costumes estão fundados em valores - o que é costumeiro é confundido, muito freqüentemente, com o que é bom. E, então, porque algu- mas ações reprováveis tornam-se costumeiras em algumas instâncias sociais, as pessoas são levadas a afirmar que "já que é costumeiro, não é mau".

Muitas vezes, verifica-se isso no campo da avaliação - recorremos a determinadas formas de avaliação habituais, já "consagradas", sem perguntar por sua consistência ou coerência. São "costumeiros" os exames vestibulares, logo... serão bons?

É para evitar equívocos dessa natureza que recorremos à ética. Diferente da moral, que tem um caráter normativo, a ética tem um caráter reflexivo. É com base em seus princípios - o respeito, a justiça, a solidariedade - que as ações morais podem ser julgadas.

Essa é uma distinção que pretende ser esclarecedora, no sentido de levar ao reconhecimento da presença da moral, em todas as ações e relações, e de uma costumeira ausência da ética, em boa parte delas, em nosso contexto social, nas instituições escolares, nas salas de aula.

É porque temos necessidade dessa presença da ética que precisamos nos mobilizar para identificá-la e promovê-la com firmeza. No terreno da avaliação educacional, que aqui nos interessa especificamente, a ética tem o papel de indagar se as ações avaliativas estão fundadas em princípios que levam à promoção do bem comum, da dignidade humana, da vida feliz.

\section{Igualdade na diferença}

\section{Os professores moçambicanos preocupavam-se com}

a justiça na avaliação. Alguns apontavam a dificuldade de realizar uma avaliação justa, em virtude da presença da subjetividade no processo. A partir de suas indagações, tivemos oportunidade de refletir sobre a falsa dicotomia objetividade/subjetividade nas ações e relações humanas. Objetividade e subjetividade são perspectivas do conhecimento, o qual se define exatamente como uma relação que envolve sujeito e objeto. Esta relação tem um caráter dialético - impossível separar os seus pólos.

Assim, pelo fato de haver sempre um sujeito "conhecedor", é impossivel deixar de haver subjetividade no conhecimento e na ação. Isso se evidencia se retomarmos o que dissemos sobre os valores presentes no contexto humano. Valores são atribuídos levando-se em conta características que os objetos, quaisquer que sejam eles, têm, independentemente da relação com o sujeito, mas se configuram exatamente a partir da signifi- 
cação que os sujeitos dão a essas características.

Assim, não é a presença da subjetividade que prejudica o trabalho educativo ou a avaliação. 0 que pode causar prejuízo é a forma como se atribuem os valores, quando se desconsideram os princípios que devem fundamentar a convivência humana, o processo educativo, os mecanismos de avaliação.

Levando em conta a subjetividade, somos remetidos também à necessidade de considerar a diversidade e a diferença. É exatamente aí que ganha relevo a questão da justiça.

Pelo princípio da justiça, afirma-se a igualdade na diferença. Somos diferentes: homens e mulheres; brancos, negros, de diversas etnias; idosos, adultos, jovens e crianças. Mas somos iguais em direitos, iguais no direito de ter direitos, de criar direitos. Somos, portanto, diferentes e iguais. 0 contrário de igual não é diferente. É desigual, e tem uma conotação social e política. A afirmação da identidade se dá na possibilidade da existência da diferença e na luta pela superação da desigualdade.

Perguntar pela presença da justiça nas ações de avaliação é indagar se elas, como elementos de um processo mais amplo que é a educação, contribuem para que se cumpra a finalidade desse processo: a criação e a partilha da cultura, a construção da humanidade, a afirmação da cidadania.

Pode parecer enfático fazer essa afirmação. Entretanto, é preciso que nós a reiteremos, sempre: quando avaliamos, no campo da educação, educamos. E temos que nos indagar se estamos efetivamente educando de acordo com os princípios éticos, para além do que se costuma determinar moralmente. Quantas vezes 0 processo avaliativo não tem contribuído para a instalação de desigualdades, quantas vezes a avaliação não se apresenta como um instrumento de dominação e controle, apesar dos discursos que mencionam igualdade e diálogo?

Parece-nos que é exatamente na avaliação que (os professores) mais negam seus discursos progressistas, que retomam, com mais determinação, a prática do monólogo com o aluno, que usam o espaço para o exercício do poder, um poder que se harmoniza com a ordem social vigente.

(...) Não conseguem analisar a avaliação do estudante como apenas uma limitada faceta de um processo mais amplo (Sordi, 1995, p. 23).

\author{
...a avaliação não é algo \\ isolado da organização \\ curricular, é elemento \\ constituinte dessa \\ organização. Por isso \\ mesmo é que se insiste \\ no caráter processual e \\ contínuo da avaliação, no \\ seu caráterformativo.
}

Vale retomar a idéia de que, ao trazer a justiça para o processo educativo/avaliativo, cria-se espaço para a igualdade e a diferença. Comte-Sponville (1996, p. 75) afirma que "a igualdade não é tudo". E indaga: "Seria justo o juiz que infligisse a todos os acusados a mesma pena? 0 professor que atribuísse a todos os alunos a mesma nota?". É preciso reconhecer a diferença - de natureza, de condições - dos que são submetidos à avaliação, uma vez que é a partir desse reconhecimento que se pode criticamente estabelecer critérios e encaminhar ações.

\section{Avaliação, "ensinação" e aprendizagem}

\section{Tenho chamado atenção para uma pergunta que é feita} por um amigo e colega, o professor Douglas Santos: o que ensinamos quando ensinamos uma determinada disciplina? - "O que realmente ensinamos quando procuramos explicar cada um dos temas que dão identidade às nossas disciplinas e às nossas aulas?" (Santos, 2004, p. 35). A resposta é: não ensinamos apenas aquelas disciplinas. Segundo Santos, "ensinar conteúdos ultrapassa os limites aparentes de nosso discurso e das afirmações que nele estão contidas".

Isso quer dizer que, ao ensinar qualquer disciplina, criamos possibilidades de o educando desenvolver a capacidade de dominar as estruturas que são usadas para construir o pensar e, além disso, possibilidades de desenvolver a capacidade de agir e sistematizar sua ação. Mais ainda: não é apenas um amplo conjunto de habilidades que se desenvolve, também se configuram atitudes em relação à realidade e à convivência social. A atitude do professor ensina. 
Ora, a avaliação não é algo isolado da organização curricular, é elemento constituinte dessa organização. Por isso mesmo é que se insiste no caráter processual e contínuo da avaliação, no seu caráter formativo. Assim, com relação à avaliação, há uma pergunta decorrente daquela que nos apresenta Douglas Santos: "O que se ensina quando se avalia algo no contexto educativo?”.

Retomo a pergunta levando em consideração a forma como a avaliação tem sido, muitas vezes, realizada na escola: de forma fragmentada, em momentos específicos. Há, então, "a semana de provas", "o dia da avaliação”. Nesses momentos, supostamente, "não há aulas". Há uma interrupção no processo de ensinar, que ocorre nas aulas. A "ensinação" e a aprendizagem dão lugar à avaliação.

É propositalmente que pinto com cores mais fortes o que costuma acontecer - reconheço que essa forma de considerar o trabalho na escola não é própria da maioria dos professores. Entretanto, ela faz parte de um imaginário que se expressa na fala dos alunos: "Não estamos tendo aula (aprendendo?) nesta semana, pois é a 'semana dos exames'". Efetivamente, numa "parada para avaliar" acontece algo diferente da relação cotidiana de professores e alunos. Mas não se deixa de ensinar e aprender. E o que se ensina e se aprende naquele momento?

A organização das questões propostas aos alunos, a forma como se esclarecem os objetivos e critérios, a atitude do professor ao apresentá-los, tudo isso ensina, para além da sistematização de determinadas estruturas de conhecimento. Sem dúvida, há que se estar atento para a dimensão técnica do processo (será mesmo considerado um processo?), mas não se podem esquecer suas implicações políticas e éticas.

No filme Pro dia nascer feliz, de João Jardim,,$^{1}$ entre diversas cenas inquietantes e constrangedoras, o cineasta nos faz participar daquela em que se mostra uma sessão do Conselho de Classe de uma das escolas enfocadas no filme. As professoras estão discutindo o desempenho de um aluno que tem um comportamento extremamente problemático nas aulas de todas as disciplinas, e cujo rendimento se encontra longe do desejável. Os conceitos que cada professora traz são muito baixos e levariam imediatamente a uma reprovação. Entretanto, elas se perguntam se vale a pena reter o aluno, uma vez que as condições para a recuperação são quase inexistentes e a reprovação levaria o aluno a abandonar a escola.
Em nenhum momento as professoras fazem referência explícita à questão da justiça na avaliação que estão realizando. Mas é isso o que está implícito. E é evidente o mal-estar que causa a ausência de recurso a qualquer fundamento para os encaminhamentos que são propostos. Problematiza-se, ali, não apenas a situação do aluno, como também a das próprias professoras e da escola. E, sem dúvida, a da sociedade, carente de justiça. No Brasil, lugar do documentário; em Moçambique, onde os alunos-professores revelam suas preocupações. Em tantas partes do mundo. Esteban (2003, p. 32) nos diz que

...muitas vezes, o que dá sentido às palavras, atos, produções, processos, possibilidades, carências, está silenciado, nem por isso, ausente. Apenas invisibilizado no discurso e nas práticas. Para avaliar, é preciso produzir instrumentos e procedimentos que nos ajudem a dar voz e visibilidade ao que é silenciado e apagado. Com muito cuidado, porque a intenção não é melhor controlar e classificar, mas sim melhor compreender e interagir.

\section{Crítica e utopia}

“Não mexa na minha avaliação!” é o título que Perrenoud (1993, p. 173) dá a um de seus trabalhos. Esta exclamação é, segundo Perrenoud, aquela com a qual se reage a qualquer mudança no sistema de avaliação, uma vez que ela implicaria uma mudança mais ampla, do sistema educacional: "significa pôr em questão um conjunto de equilíbrios frágeis e parece representar uma vontade de desestabilizar a prática pedagógica e o funcionamento da escola", afirma ele.

Há, sem dúvida, uma verdade na afirmação de Perrenoud. Se considerarmos que a avaliação não pode estar desarticulada de outros elementos do processo educativo, sendo considerada até um dos elementoschave desse processo, mexer nela poderia colocar em risco o edifício supostamente seguro do trabalho realizado na escola.

É importante, portanto, pensar a avaliação no contexto da proposta curricular e, esta, no interior de um projeto pedagógico, elaborado com a participação de toda a equipe escolar e levando em conta as necessidades concretas da sociedade e os limites e possibilidades para a construção coletiva de uma educação democrática e justa (Rios, 2000). 


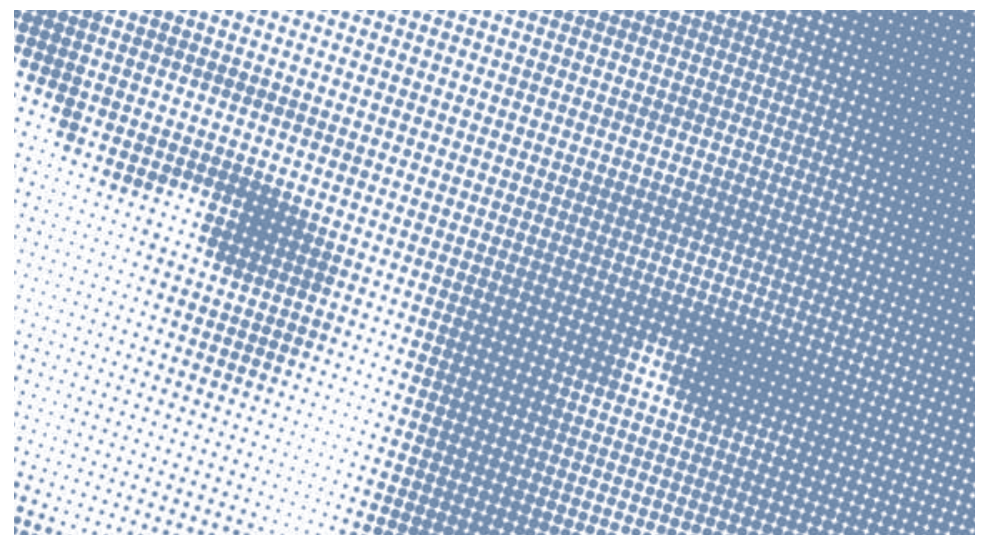

Se atualmente a discussão em torno da organização curricular amplia a noção de conteúdos, que não abrange apenas os conceitos, como também os comportamentos e atitudes, é preciso ampliar ainda a noção de avaliação. Se se pretende realizar uma formação integral, é necessário que a avaliação também o seja. Trata-se de olhar criticamente para todo o trabalho que se realiza na escola e não somente o do aluno. E quando se voltar para o trabalho do aluno, é preciso que, numa relação de respeito e justiça, professores e professoras procurem estabelecer princípios e definir instrumentos e ações que encaminhem para os objetivos desejados.

O terreno da avaliação é um espaço privilegiado para que se encontre a possibilidade de concretização da proposta de incluir a ética no currículo das escolas como algo que, não constituindo uma área ou disciplina, articula-se com elas de maneira que os professores e as professoras possam trabalhar, de maneira integrada, o conhecimento específico de suas áreas e as questões relacionadas aos valores e ao convívio social (Brasil, 1998). O respeito, a justiça, a solidariedade, o diálogo, que devem estar presentes nas relações no interior da escola e, desta, com a sociedade, devem ser os referenciais para o estabelecimento de critérios e devem fundamentar o trabalho na sala de aula e o processo continuado de avaliação desse trabalho.

Retomo a certeza do professor que afirma que "a avaliação é um gesto crítico que visa trazer justiça na relação professor-aluno". Ela se converte numa dúvida quando percebemos seu caráter categórico: "a avaliação é...". Na verdade, a avaliação deve ser... Este "dever ser”, revestido não de um caráter impositivo e controlador, e sim entendido como expressão do desejo e da necessidade, leva-nos ao caráter utópico que se abriga na ética.
Como tentativa de compreensão, o exercício crítico da ética volta-se para um ideal - algo desejado e necessário, que se anuncia no futuro e cuja possibilidade já se encontra inscrita no real e no presente. Ainda não encontramos no contexto educativo a avaliação justa do jeito que pensamos ser desejável. Mas é nesse próprio contexto que se revelam ações que nos dão esperança, que indicam a possibilidade de contribuir, na escola, para a construção da sociedade democrática e solidária. As certezas - sempre provisórias - continuam a conviver com as dúvidas que nos provocam a seguir em frente, enfrentando os desafios.

\section{Referências}

AFONSO, Almerindo Janela. Avaliação educacional: regulação e emancipação. São Paulo: Cortez, 2000.

. Avaliar a escola e a gestão escolar: elementos para uma reflexão crítica. In: ESTEBAN, Maria Teresa (Org.). Escola, currículo e avaliação. São Paulo: Cortez, 2003. p. 38-56.

BARBIER, Jean-Marie. A avaliação em formação. Porto: Edições Afrontamento, $\mathrm{s} / \mathrm{d}$.

BARLOW, Michel. Avaliação escolar: mitos e realidades. Porto Alegre: Artmed, 2006.

BRASIL. Parâmetros curriculares nacionais: terceiro e quarto ciclos do Ensino Fundamental. Brasília: MEC/Secretaria de Educação Fundamental, 1998.

COMTE-SPOVILLE, André. Pequeno tratado das grandes virtudes. São Paulo: Martins Fontes, 1996.

DIAS SOBRINHO, José. Avaliação - Políticas educacionais e reformas da educação superior. São Paulo: Cortez, 2003.

Educação e avaliação: técnica e ética. In: DIAS SOBRINHO, José; RISTOFF, Dilvo (Org.). Avaliação democrática: para uma universidade cidadã. Florianópolis: Insular, 2002.

ESTEBAN, Maria Teresa. Ser professora: avaliar e ser avaliada. In: ESTEBAN, Maria Teresa (Org.). Escola, currículo e avaliação. São Paulo: Cortez, 2003. p. $13-37$.

(Org.). Escola, currículo e avaliação. São Paulo: Cortez, 2003.

HADJI, Charles. Avaliação desmistificada. Porto Alegre: Artmed, 2001.

PERRENOUD, Philippe. Não mexam na minha avaliação! Por uma abordagem sistêmica da mudança pedagógica. In: ESTRELA, Albano; NÓVOA, António (Org). Avaliações em educação: novas perspectivas. Porto: Porto Editora, 1993. p. 171-191.

RIOS, Terezinha A. A dimensão ética da avaliação. Pró-Posições, Campinas, Faculdade de Educação da Unicamp, v. 10, n. 2, p. 94-101, maio 2000.

Ética e competência (1993). 16. ed. São Paulo: Cortez, 2006.

Compreender e ensinar: por uma docência da melhor qualidade (2001). 6. ed. São Paulo: Cortez, 2006.

ROMÃo, José Eustáquio. Avaliação dialógica - desafios e perspectivas. São Paulo: Cortez, 1998.

SANTOS, Douglas. Uma consultoria para a educação escolar no Amapá - Relatório de discussões. São Paulo: PUC-SP/Instituto de Estudos Especiais, 2004.

SORDI, Mara Regina Lemes de. Entendendo as lógicas da avaliação institucional para dar sentido ao contexto interpretativo. In: VILLAS BOAS, Benigna M. de F. (Org.). Avaliação: políticas e práticas. Campinas: Papirus, s/d. p. 65-81.

VILLAS BOAS, Benigna M. de F. (Org.). Avaliação: políticas e práticas. Campinas: Papirus, s/d.

\section{Notas}

1 Pro dia nascer feliz. Documentário. João Jardim (diretor). Ravina Filmes/Fogo Azul Filmes. Brasil, 2006. 